\title{
The Inner and Outer Qualities of Extracellular Vesicles for Translational Purposes in Breast Cancer
}

\author{
Esther Schwich and Vera Rebmann* \\ Institute for Transfusion Medicine, University Hospital Essen, University Duisburg-Essen, Essen, Germany
}

Breast cancer $(\mathrm{BC})$ is the second most common cause of cancer mortality of women worldwide. BC is a systemic disease with a highly heterogeneous course of disease. Therefore, prognostic and diagnostic biomarkers are required to improve the clinical risk management. Cancer-derived or cancer-associated extracellular vesicles (EVs) procured from the bloodstream of BC patients offer a novel platform for the qualitative and quan-

OPEN ACCESS

Edited by: Miroslaw Kornek,

Universitätsklinikum des

Saarlandes, Germany

Reviewed by:

María Yáñez-Mó,

Universidad Autonoma de

Madrid, Spain

Kishore Kumar Jella,

Emory University, United States

Stefano Fais,

Istituto Superiore di Sanità, Italy

*Correspondence:

Vera Rebmann

vera.rebmann@uk-essen.de

Specialty section:

This article was submitted

to Immunological Tolerance and Regulation,

a section of the journal

Frontiers in Immunology

Received: 31 January 2018 Accepted: 08 March 2018

Published: 26 March 2018

Citation:

Schwich E and Rebmann V (2018)

The Inner and Outer Qualities of Extracellular Vesicles for Translational

Purposes in Breast Cancer.

Front. Immunol. 9:584.

doi: 10.3389/fimmu.2018.00584 titative screening and establishment of biomarkers. Here, we focus on common aspects of EVs, on the function of $\mathrm{BC}$-derived $\mathrm{EVs}$ and their translational potential considering the EV abundancy, intravesicular as well as outer membrane-anchored composition and current challenges of implementation in clinical practice.

Keywords: breast cancer, biomarker, liquid biopsy, extracellular vesicles (EV), exosomes, micro-RNA, HLA-G, HER-2/neu

\section{INTRODUCTION: BREAST CANCER (BC) PROGNOSIS AND DIAGNOSIS}

Breast cancer is the second most common cause of cancer mortality of women worldwide and the most prevalent type of cancer among woman. It is a highly heterogeneous disease and subclassified according to the status of the hormone receptors progesterone (PR) and estrogen (ER), overexpression/amplification of the human epidermal growth factor receptor 2 (HER-2), and the basal-like mostly triple-negative (PR-/ER-/HER-2-) subtypes (TNBC) (1). PR and ER status give information about the responsiveness to adjuvant hormonal therapy (2), whereas HER-2/neu amplification is associated with tumor aggressiveness and chemoresistance (3). TNBC subtypes have the worst overall and disease-free survival compared with other subtypes (4), whereas nonmetastatic $\mathrm{BC}$ is associated with a long-term survival $(5,6)$. Conventional screening methods encompassing mammography and tissue biopsy investigations and the consequential multimodality therapy approaches including surgery, chemo-, radiation-, and hormone therapy, and antigen-targeted treatments with monoclonal antibodies, have definitely improved $\mathrm{BC}$ survival of low-grade and endocrine-responsive tumors (7). For these BC subtypes, the timeline of early detection is less critical than for high-grade or highly proliferating $\mathrm{BC}$ subtypes. Although the $\mathrm{BC}$ classification is informative, further molecular markers considering alterations in systemic proteomic, glycoproteomic, immune, and nucleic acid profiles, generally observed in BC and other solid malignancies (8) should be established for a better personalized risk management. Ideally, biomarkers should allow refining (i) early detection of $\mathrm{BC}$, (ii) early prediction of relapse, and (iii) chemotherapy response. Heterogeneity of $\mathrm{BC}$ evolution within $\mathrm{BC}$ patients with tumor spread often leads to mixed clinical responses. Here a molecular profiling of metastatic tumors 
and a monitoring of metastatic disease response would help to overcome tissue-based diagnostics, especially considering that BC metastasis are commonly localized at relatively inaccessible anatomic sites, such as bone, liver, and lung. Thus, liquid biopsy, procured from the bloodstream, offers as a non-invasive screening source a platform for the qualitative and quantitative detection of cancer-derived or cancer-associated entities, e.g., extracellular vesicles (EVs), circulating tumor DNA (ctDNA), or circulating tumor cells (CTCs). Principally, the genetic information and molecular composition of entities acquired by liquid biopsy should be equal to tissue biopsy, though complications of the latter are avoided $(9,10)$. In addition, the repeated sampling permits the monitoring of clonal dynamics throughout the course of therapy and early identification of therapeutic resistance drivers or early relapse (9). Analysis of EVs encompasses several advantages over CTCs and ctDNA due to their higher abundancies and stability in the bloodstream, and their functionality in supporting tumor-host cross talk or tumorigenesis in BC. Here, we focus on common aspects of EVs, on the function of BC-derived EVs, their translational potential considering abundancy, intravesicular as well as outer membrane-anchored composition, and challenges of implementation in clinical practice.

\section{THE STATUS QUO OF COMMON ASPECTS OF EVs}

\section{The Four Categories of EVs}

Extracellular vesicles are bi-lipid membrane vesicles secreted by a broad range of cells including tumor cells. The cell of origin controls EV assembly making them highly heterogeneous in size, membrane composition, and molecular content of protein and genetic information (11). According to their size and biogenesis, EVs can be classified in several subtypes: small EVs designated as exosomes $(70-150 \mathrm{~nm})$ are secreted via a multivesicular-body endocytic process (12); microvesicles (100-1,000 nm) are formed by outward budding and scission of the plasma membrane (13); apoptotic bodies (>500 $\mathrm{nm}$ ) are generated from plasma membrane blebs of apoptotic tumor cells (14) and oncosomes are non-apoptotic membrane blebs of amoeboid cancerous cells $(>1,000-10,000 \mathrm{~nm})(15)$. Hitherto, discrimination relies primarily on their size as the exclusive identification of a specific subtype is virtually impossible by certain invariant housekeeping markers.

\section{The Outer Membrane-Anchored and Intravesicular Composition of EVs}

The outer membrane-anchored composition includes transmembrane or lipid-bound extracellular proteins. The intravesicular or rather the inner content encompasses proteins, lipids, metabolites, and nucleic acids as DNA, mRNA, microRNA, and other non-coding RNAs. Both compositions reflect their parent cell and their activating/health status at time point of generation $(16,17)$. In general, the lipid membrane of EVs prevents their cargo from enzyme degradation, preserves their functionality and facilitates their transfer even over a long distance $(18,19)$.
Current characterization and verification of EVs is based on the detection of typical EV markers including (i) transmembrane or lipid-bound extracellular proteins, e.g., tetraspanins, cell adhesion molecules, integrins (20-22) and (ii) cytosolic proteins with membrane- or receptor-binding capacity as members of endosomal sorting complexes required for transport of EVs as the tumor susceptibility gene $101(20,23)$. According to recommendation of the international society for EVs (20) EV preparations should be semiquantified for at least one EV-enriched protein of each group mentioned earlier and one appropriate negative control, being an intracellular protein not associated with the plasma membrane or endosomes.

\section{The Functional Implication of EVs}

Extracellular vesicles can exert their functions via three mechanisms: (i) receptor-ligand interaction, (ii) direct fusion with plasma membrane, and (iii) internalization of EVs from target cells by phagocytosis, clathrin- and caveolin-mediated endocytosis or micropinocytosis, to transfer genetic information/bioactive molecules to target cells or to participate in intracellular signaling (24). Horizontal transfer of genetic information allows EVs to regulate the recipient cell at a posttranscriptional level, retaining features of the originating tissue or of its microenvironment (11). Depending on their composition, EVs can orchestrate multiple systemic processes such as cell-to-cell communication, and participate in the maintenance of normal physiology $(25,26)$. Furthermore, EVs can induce gene expression modifications, and activate or suppress immunological responses introducing homeostasis of immune tolerance (27-29). In tumorigenesis, EVs can promote tumor progression by inducing normal cell transformation, remodel the surrounding parenchymal tissue, and modulate the immune system $(25,26,28)$. Interestingly, EVs can mediate radiation-induced bystander signaling transferring radiation effects to non-targeted cells $(30,31)$, and composition of EVs can be modified upon environmental stress such as radiation $(32,33)$.

\section{The Challenge to Isolate Pure EV Fractions}

Extracellular vesicle purification bears challenges due to their small size and physicochemical properties (34). So far, the choice of purification technique clearly depends on the scientific issue being addressed and on further downstream applications used. Methods for purification encompass precipitation kits, size-exclusion chromatography, and sequential centrifugation followed by an ultracentrifugation step, with the latter being the current gold standard in the field $(35,36)$. Disadvantages such as reproducibility, potential vesicular disruption impairing the functionality of EVs, or contamination with non-vesicular components, impede the establishment of a standardized method (37). A novel method based on a commercially available bindelute size-exclusion chromatography might revolutionize EV purification (37).

\section{THE STATUS QUO OF EVs IN BC}

Extracellular vesicles resemble cancer-derived characteristics and a plethora of proteins is often enriched compared with their cell of 
origin (38). Hence, recent cancer research is focusing on defining EV subpopulations based on their cargo as an enrichment of a specific cargo in EVs promotes a wide-range of cellular functions in the context of malignancies.

\section{The Functional Implication of EVs Derived From BC Cell Lines}

Different BC cell lines secrete EVs with distinct protein signatures in quantities correlating with increasing metastatic potential, likely facilitating cell migration and metastasization. EVs from murine $\mathrm{BC}$ cell lines with metastatic features harbor a distinct set of membrane-anchored proteins including Ceruloplasmin and Metadherin which promote cancer metastasis (39). A potential mediator of BC cell activity, motility, and metastasis seems to be exosomal CD81 secreted from human fibroblasts triggering activation of the autocrine Wnt-planar cell polarity signaling pathway (40). Accordantly, mesenchymal stem-cell-derived EVs promote migration of MCF-7 BC cells by activation of the Wntsignaling pathway (41). Furthermore, EVs released by human BC cell lines containing the epidermal growth factor receptor (EGFR) ligand amphiregulin increase invasiveness of recipient cancer cells (42). Interestingly, EVs carrying the apoptosis inhibitor Survivin-a protein overexpressed in BC tissues and associated with chemo- and radiotherapy resistance-are linked to tumor recurrence and reduced patient's survival. The TNBC cell line MDA-MB-231 releases elevated numbers of Survivinrich EVs upon chemotherapy, thereby promoting tumor survival (43). Furthermore, glutathione S-transferase P1-containing EVs derived from chemoresistant cells seem to induce a drugresistant phenotype (44). Consistently, therapeutic-induced senescent TNBC cells release enhanced levels of EVs containing key factors linked to cell proliferation, ATP depletion, apoptosis, and the senescence-associated secretory phenotype (45). EVs secreted by tumor-associated macrophages (TAM) can promote $\mathrm{BC}$ invasion and metastasis formation, whereas BC-EVs carrying miR-16 inhibit TAM infiltration and polarization of the tumorsupportive M2 macrophage phenotype $(46,47)$. In addition, compared with EVs from non-tumorigenic cells, miRNA are enriched in BC-EVs, and these EVs can actively convert premiRNA into mature miRNA (48). Cells of the non-malignant mammary epithelial cell line HMLE transform into tumorigenic cells upon exosomal uptake of MDA-MB-231-derived miR-10b. Strikingly, EVs can contain double-stranded DNA which represents the entire genome mirroring the mutational status of the parental tumor cell $(49,50)$. Together, these and other studies (51-53) provide the concept of EVs being a central player in the pathogenesis of BC. Due to the miscellaneous decisive roles of EVs in tumor-promoting processes great efforts have been made to investigate its translational potential as a circulating biomarker in blood of BC patients.

\section{The Translational Potential of Circulating Blood EV Counts in BC}

Likely due to the extracellular acidity of malignant tumors, $\mathrm{BC}$ and other tumor entities produce EVs in relative high abundance compared with normal cells which can be locally restricted or systemically released (24, 54-57). Hence, EV count may serve as a surrogate marker for disease detection, whereas EV biochemistry may provide molecular markers to assess tumor severity (58). Systemically released EVs are detectable in nearly all body fluids including blood and ascites fluids, or pleural effusions (59). In primary, non-metastatic, locally advanced BC patients undergoing neoadjuvant chemotherapy (NACT) EV counts are associated with nodal status before NACT suggesting that tumor cells resident in lymph nodes release enhanced EV levels into circulation (54). In addition, EV counts strongly correlate with tumor size before NACT (54). As enhanced EV count before NACT is associated with therapy failure, it is likely that high amounts of EVs negatively impact therapy response. Post NACT high EV levels are associated with a reduced 3-year progression-free and overall survival (54). Interestingly, high EV levels are inversely associated with presence of CTCs (54). Here, it can be hypothesized that CTCs consume EVs for maintaining their BC phenotype in the periphery. Thus, EVs and CTCs isolated from one patient at the same time point uncover different, but yet complementary information on BC disease status and prognosis (60). Consequently, EVs and CTCs should be analyzed simultaneously from liquid biopsies to evaluate minimal residual disease and to improve the understanding of the underlying biology of BC heterogeneity (54).

\section{The Translational Potential of Intravesicular Components in Circulating Blood EVs of BC}

Expression of the cancer marker focal adhesion kinase is significantly elevated in $\mathrm{BC}-\mathrm{EV}$ s in ascending order with disease stage (61). Similar, levels of carcinoembryonic antigen and cancer antigen 15-3 in circulating EVs of BC patients are linked to cancer progression (62), but do not facilitate a marker of early stage (63). In addition, the proapoptotic splice variant Survivin-2B packaged into circulating serum EVs is discussed as an early diagnostic and/or prognostic marker in BC (64). HSP72 present in EVs from breast and other solid cancers interacts with the toll-like receptor 2 on myeloid-derived suppressor cells which induces their activation and thus promotes an immunosuppressive pathway involved in tumor-induced tolerance (65). Besides intravesicular proteins, a plethora of microRNAs involved in $\mathrm{BC}$ progression has been identified in BC-derived EVs $(62,66)$. Of note, serum-derived $\mathrm{EVs}$ of BC patients can contain (i) the RNA-induced silencing complex-loading complex proteins, (ii) the enzyme Dicer, (iii) the transactivating response RNA binding protein (TRBP), and (iv) argonaute 2, which are essential compounds required for miRNA biogenesis. Thus, blood EVs have the potential capacity to convert pre-miRNAs to mature miRNAs (48). Indeed, levels of miR-21 and miR-1246 are elevated in plasma-EVs from BC patients (67) than in healthy controls. Moreover, higher levels of miR-105 in BC serum EVs are associated with metastasis formation representing a potential marker for advanced $\mathrm{BC}$ and prognostic outcome during course of disease (68). In serum of BC patients, vesicular, but not cell-free circulating, miR-101, miR-372, and miR-373 are increased compared with healthy 
controls, the latter being suggested to be indicative for TNBC phenotype (69).

\section{The Translational Potential of Outer Membrane-Anchored Components in Circulating Blood EVs of BC Patients}

Besides the vesicular packaging of cancer cell-specific cargoes, diverse cancer markers are increased on the outer surface of EVs derived from BC patients compared with healthy controls. Expression of the oncogenic marker CD24 on EVs might be clinically relevant in $\mathrm{BC}$ and ovarian carcinoma (70). In addition, expression levels of EGFR are increased in BC-EVs in a disease stage dependent manner (61). Not only the tumor-derived molecules MUC1, EGFR, and EpCAM but also the matrix metalloproteinase inducer EMMPRIN are identified in blood-derived EVs of patients with BC and other solid tumor entities (38). Presence of these molecules was significantly associated with a reduced overall survival. Furthermore, the transient receptor potential channel (TRCP5) integrated in the membrane of EVs can mediate chemoresistance to chemo-sensitive BC cells. Indeed, levels of BC plasma-derived EVs carrying TRCP5 correlated with its expression levels in BC tissues and with tumor response to chemotherapy (71). Interestingly, chemotherapy can increase the CD144 or CD62e EV subpopulation, which might be indicative for chemotherapy-related thrombogenicity or vascular damage (72). Glypican-1 (GPC1) is a membrane-anchored protein overexpressed in $\mathrm{BC}$ and pancreatic cancer (73) modulating mitogenic effects of various heparin-binding growth factors in these tumors $(74,75)$. Consequently, presence of GPC1-EVs in the blood of these patients is discussed as promising biomarker (73). Several additional cancer markers have been identified on BC-EV s including HER-2 and HLA-G, both being associated with tumor proliferation, invasiveness, drug resistance, and metastasis formation $(76,77)$. HER-2 serves as a prognostic indicator for tumor aggressiveness and chemoresistance. EVs derived from HER-2-overexpressing BC cells have been suggested to contribute to this, as they express active HER-2 which potentially binds to the HER-2 antibody, thereby impairing therapy outcome (76). Moreover, resistance to HER-2-targeted therapy seems to be associated with increased levels of TGF $\beta 1$ levels in blood EVs derived from HER-2+ BC patients (78). HLA-G, which induces immune tolerance and mediates tumor escape $(79,80)$, is a biomarker for malignancies comparable to other immune checkpoint molecules $(77,81)$. High levels of HLA-G in EV fractions positively correlate with disease progression of primary, non-metastatic, locally advanced BC patients undergoing NACT (54). In addition, presence of stem-cell like CTCs is positively associated with high HLA-G levels in EV fractions (54).

\section{THE CHALLENGE TO ESTABLISH AND TO INTEGRATE EV-DERIVED BC BIOMARKERS IN THE CLINIC}

Hitherto, studies on circulating blood EVs dealing with EV counts and phenotypes in $\mathrm{BC}$ patients clearly demonstrated the translational potential. However, isolation and characterization methods and corresponding analysis instrumentation limit the translational power of EV research. Instrumentation used for determination of shape, size, and number include electron microscopy, nanoparticle tracking analysis, dynamic light scatter, and resistive pulse sensing. Although the three latter are suitable for high-throughput analyses, these techniques fail to distinguish $\mathrm{BC}$-derived/associated EVs from the total $\mathrm{EV}$ population in the blood. Selective identification of discrete sets of EVs can only be achieved via BC-derived/associated molecules expressed on the outer EV membrane. The issue is that due to the small diameter size, the vast majority of EVs present only 10 copies of a protein, whereas cells express thousand copies (82). Thus, sensitivity of common flow cytometers reaches their limitation to detect EV populations (83), albeit labeling these few proteins with antibodies conjugated with bright fluorescence dyes. In addition, as multiple small vesicles are simultaneously illuminated as a swarm, EV count within a distinct population is diminished $(84,85)$. Nevertheless, as accurate determination of EV-derived biomarkers and simple test performing are prerequisite for the successful integration into daily clinical practice, flow cytometric methods appear to be the best choice due to their high throughput and multiplexed capabilities. New methods such as flow cytometric scatter ratio (86) are promising approaches to overcome these difficulties.

A second issue is related to the design of clinical studies and how to define disease markers in BC. By comparing circulating blood EVs in BC patients at diagnosis, pre- and posttreatment, during follow-up, and correlating with clinical and pathologic development, we might be able to predict therapeutic response and patient prognosis. For the establishment of reliable early prediction markers in $\mathrm{BC}$, it is inevitable to analyze blood-derived EVs before tumor diagnosis. This implies a long-term observational study of continuous blood sampling enrolling women undergoing mammography with initial negative test results until tumor diagnosis. This study design, however, is only feasible in national study centers.

\section{CONCLUSION AND PERSPECTIVE}

At present, clinical studies clearly highlight the translational potential of blood-derived EVs in BC. In future, enumeration and qualitative/qualitative evaluation of EVs, expressing a distinct set of tumor-derived/associated markers, will provide crucial information for the risk management of BC patients in conjunction with their physical examination. Due to the fact that different tumor entities share common phenotypes considering hypoxia, nutrient supply and extracellular acidity, it is likely that a set of certain EV subpopulations of $\mathrm{BC}$ patients are meaningful in the integration of risk management protocols for other malignancies. To guarantee a fast implementation of the translational power of blood EVs in clinical practice, it is essential (i) to establish innovative methods for EV isolation and characterization, (ii) to design and conduct clinical discovery and validation studies permitting the monitoring of clonal dynamics of $\mathrm{BC}$ and other solid malignancies throughout the course of therapy, and (iii) to establish long-term observational control 
cohorts. The latter one can best be realized for $\mathrm{BC}$ as woman undergo serial preventive medical examination by mammography. The translational power of EVs is not restricted to risk management of cancer patients regarding early identification of tumor development, therapeutic resistance drivers, or early relapse. Introduction of therapeutically engineered endogenous EVs represents promising novel strategies for the efficient and targeted delivery of therapeutics which reduce the cytotoxic side effects of current cancer treatments (87-89).

\section{REFERENCES}

1. Perou CM, Sørlie T, Eisen MB, van de Rijn M, Jeffrey SS, Rees CA, et al. Molecular portraits of human breast tumours. Nature (2000) 406(6797): 747-52. doi:10.1038/35021093

2. Mwakigonja AR, Lushina NE, Mwanga A. Characterization of hormonal receptors and human epidermal growth factor receptor- 2 in tissues of women with breast cancer at Muhimbili National Hospital, Dar es salaam, Tanzania. Infect Agent Cancer (2017) 12:60. doi:10.1186/s13027-017-0170-5

3. Clark GM, McGuire WL. Follow-up study of HER-2/neu amplification in primary breast cancer. Cancer Res (1991) 51(3):944-8.

4. Onitilo AA, Engel JM, Greenlee RT, Mukesh BN. Breast cancer subtypes based on ER/PR and Her2 expression: comparison of clinicopathologic features and survival. Clin Med Res (2009) 7(1-2):4-13. doi:10.3121/cmr.2009.825

5. Buchholz TA, Hunt KK, Whitman GJ, Sahin AA, Hortobagyi GN. Neoadjuvant chemotherapy for breast carcinoma: multidisciplinary considerations of benefits and risks. Cancer (2003) 98(6):1150-60. doi:10.1002/cncr.11603

6. Jemal A, Siegel R, Xu J, Ward E. Cancer statistics, 2010. CA Cancer J Clin (2010) 60(5):277-300. doi:10.3322/caac.20073

7. Mittal S, Kaur H, Gautam N, Mantha AK. Biosensors for breast cancer diagnosis: a review of bioreceptors, biotransducers and signal amplification strategies. Biosens Bioelectron (2017) 88:217-31. doi:10.1016/j.bios.2016.08.028

8. Pernikarova V, Bouchal P. Targeted proteomics of solid cancers: from quantification of known biomarkers towards reading the digital proteome maps. Expert Rev Proteomics (2015) 12(6):651-67. doi:10.1586/14789450.2015.1094381

9. Ilie M, Hofman P. Pros: can tissue biopsy be replaced by liquid biopsy? Transl Lung Cancer Res (2016) 5(4):420-3. doi:10.21037/tlcr.2016.08.06

10. Diaz LA Jr, Bardelli A. Liquid biopsies: genotyping circulating tumor DNA. J Clin Oncol (2014) 32(6):579-86. doi:10.1200/JCO.2012.45.2011

11. Yáñez-Mó M, Siljander PR, Andreu Z, Zavec AB, Borràs FE, Buzas EI, et al. Biological properties of extracellular vesicles and their physiological functions. J Extracell Vesicles (2015) 4:27066. doi:10.3402/jev.v4.27066

12. Börger V, Bremer M, Ferrer-Tur R, Gockeln L, Stambouli O, Becic A, et al. Mesenchymal stem/stromal cell-derived extracellular vesicles and their potential as novel immunomodulatory therapeutic agents. Int J Mol Sci (2017) 18(7):E1450. doi:10.3390/ijms18071450

13. Muralidharan-Chari V, Clancy JW, Sedgwick A, D’Souza-Schorey C. Microvesicles: mediators of extracellular communication during cancer progression. J Cell Sci (2010) 123(Pt 10):1603-11. doi:10.1242/jcs.064386

14. Mathivanan S, Ji H, Simpson RJ. Exosomes: extracellular organelles important in intercellular communication. J Proteomics (2010) 73(10):1907-20. doi:10.1016/j.jprot.2010.06.006

15. Di Vizio D, Kim J, Hager MH, Morello M, Yang W, Lafargue CJ, et al. Oncosome formation in prostate cancer: association with a region of frequent chromosomal deletion in metastatic disease. Cancer Res (2009) 69(13):5601-9. doi:10.1158/0008-5472.CAN-08-3860

16. Griffiths SG, Cormier MT, Clayton A, Doucette AA. Differential proteome analysis of extracellular vesicles from breast cancer cell lines by chaperone affinity enrichment. Proteomes (2017) 5(4):E25. doi:10.3390/proteomes5040025

17. Becker A, Thakur BK, Weiss JM, Kim HS, Peinado H, Lyden D. Extracellular vesicles in cancer: cell-to-cell mediators of metastasis. Cancer Cell (2016) 30(6):836-48. doi:10.1016/j.ccell.2016.10.009

18. Valadi H, Ekström K, Bossios A, Sjöstrand M, Lee JJ, Lötvall JO. Exosomemediated transfer of mRNAs and microRNAs is a novel mechanism of genetic exchange between cells. Nat Cell Biol (2007) 9(6):654-9. doi:10.1038/ ncb1596

\section{AUTHOR CONTRIBUTIONS}

ES and VR: wrote the initial draft and read and approved the final article.

\section{FUNDING}

This work was supported by Deutsche Krebshilfe (109816). We acknowledge support by the Open Access Publication Fund of the University of Duisburg-Essen.

19. Mittelbrunn M, Gutiérrez-Vázquez C, Villarroya-Beltri C, González S, Sánchez-Cabo F, González MÁ, et al. Unidirectional transfer of microRNAloaded exosomes from T cells to antigen-presenting cells. Nat Commun (2011) 2:282. doi: $10.1038 /$ ncomms 1285

20. Lötvall J, Hill AF, Hochberg F, Buzás EI, Di Vizio D, Gardiner C, et al. Minimal experimental requirements for definition of extracellular vesicles and their functions: a position statement from the International Society for Extracellular Vesicles. J Extracell Vesicles (2014) 3:26913. doi:10.3402/jev.v3.26913

21. Andreu Z, Yanez-Mo M. Tetraspanins in extracellular vesicle formation and function. Front Immunol (2014) 5:442. doi:10.3389/fimmu.2014.00442

22. Paolillo M, Schinelli S. Integrins and Exosomes, a Dangerous Liaison in Cancer Progression. Cancers (Basel) (2017) 9(8):E95. doi:10.3390/cancers9080095

23. Nabhan JF, Hu R, Oh RS, Cohen SN, Lu Q. Formation and release of arrestin domain-containing protein 1-mediated microvesicles (ARMMs) at plasma membrane by recruitment of TSG101 protein. Proc Natl Acad Sci U S A (2012) 109(11):4146-51. doi:10.1073/pnas.1200448109

24. Zhang X, Yuan X, Shi H, Wu L, Qian H, Xu W. Exosomes in cancer: small particle, big player. J Hematol Oncol (2015) 8:83. doi:10.1186/s13045-015-0181-x

25. Zha QB, Yao YF, Ren ZJ, Li XJ, Tang JH. Extracellular vesicles: an overview of biogenesis, function, and role in breast cancer. Tumour Biol (2017) 39(2):1010428317691182. doi:10.1177/1010428317691182

26. van Balkom BW, Pisitkun T, Verhaar MC, Knepper MA. Exosomes and the kidney: prospects for diagnosis and therapy of renal diseases. Kidney Int (2011) 80(11):1138-45. doi:10.1038/ki.2011.292

27. Rebmann V, König L, Nardi Fda S, Wagner B, Manvailer LF, Horn PA. The potential of HLA-G-bearing extracellular vesicles as a future element in HLA-G immune biology. Front Immunol (2016) 7:173. doi:10.3389/fimmu.2016.00173

28. Greening DW, Gopal SK, Xu R, Simpson RJ, Chen W. Exosomes and their roles in immune regulation and cancer. Semin Cell Dev Biol (2015) 40:72-81. doi:10.1016/j.semcdb.2015.02.009

29. Delcayre A, Shu H, Le Pecq JB. Dendritic cell-derived exosomes in cancer immunotherapy: exploiting nature's antigen delivery pathway. Expert Rev Anticancer Ther (2005) 5(3):537-47. doi:10.1586/14737140.5.3.537

30. Al-Mayah AH, Irons SL, Pink RC, Carter DR, Kadhim MA. Possible role of exosomes containing RNA in mediating nontargeted effect of ionizing radiation. Radiat Res (2012) 177(5):539-45. doi:10.1667/RR2868.1

31. Jella KK, Rani S, O’Driscoll L, McClean B, Byrne HJ, Lyng FM. Exosomes are involved in mediating radiation induced bystander signaling in human keratinocyte cells. Radiat Res (2014) 181(2):138-45. doi:10.1667/RR13337.1

32. Jelonek K, Widlak P, Pietrowska $\mathrm{M}$. The influence of ionizing radiation on exosome composition, secretion and intercellular communication. Protein Pept Lett (2016) 23(7):656-63. doi:10.2174/0929866523666160427105138

33. Mutschelknaus L, Azimzadeh O, Heider T, Winkler K, Vetter M, Kell R, et al. Radiation alters the cargo of exosomes released from squamous head and neck cancer cells to promote migration of recipient cells. Sci Rep (2017) 7(1):12423. doi:10.1038/s41598-017-12403-6

34. Ramirez MI, Amorim MG, Gadelha C, Milic I, Welsh JA, Freitas VM, et al. Technical challenges of working with extracellular vesicles. Nanoscale (2018) 10(3):881-906. doi:10.1039/c7nr08360b

35. Böing AN, van der Pol E, Grootemaat AE, Coumans FA, Sturk A, Nieuwland R. Single-step isolation of extracellular vesicles by size-exclusion chromatography. J Extracell Vesicles (2014) 8:3. doi:10.3402/jev.v3.23430

36. Gardiner C, Di Vizio D, Sahoo S, Théry C, Witwer KW, Wauben M, et al. Techniques used for the isolation and characterization of extracellular vesicles: results of a worldwide survey. J Extracell Vesicles (2016) 5:32945. doi:10.3402/ jev.v5.32945 
37. Corso G, Mäger I, Lee Y, Görgens A, Bultema J, Giebel B, et al. Reproducible and scalable purification of extracellular vesicles using combined bind-elute and size exclusion chromatography. Sci Rep (2017) 7(1):11561. doi:10.1038/ s41598-017-10646-x

38. Menck K, Bleckmann A, Wachter A, Hennies B, Ries L, Schulz M, et al. Characterisation of tumour-derived microvesicles in cancer patients' blood and correlation with clinical outcome. J Extracell Vesicles (2017) 6(1):1340745. doi:10.1080/20013078.2017.1340745

39. Gangoda L, Liem M, Ang CS, Keerthikumar S, Adda CG, Parker BS, et al. Proteomic profiling of exosomes secreted by breast cancer cells with varying metastatic potential. Proteomics (2017) 17(23-24). doi:10.1002/pmic. 201600370

40. Luga V, Zhang L, Viloria-Petit AM, Ogunjimi AA, Inanlou MR, Chiu E, et al. Exosomes mediate stromal mobilization of autocrine Wnt-PCP signaling in breast cancer cell migration. Cell (2012) 151(7):1542-56. doi:10.1016/j. cell.2012.11.024

41. Lin R, Wang S, Zhao RC. Exosomes from human adipose-derived mesenchymal stem cells promote migration through Wnt signaling pathway in a breast cancer cell model. Mol Cell Biochem (2013) 383(1-2):13-20. doi:10.1007/ s11010-013-1746-z

42. Higginbotham JN, Demory Beckler M, Gephart JD, Franklin JL, Bogatcheva G, Kremers GJ, et al. Amphiregulin exosomes increase cancer cell invasion. Curr Biol (2011) 21(9):779-86. doi:10.1016/j.cub.2011.03.043

43. Kreger BT, Johansen ER, Cerione RA, Antonyak MA. The enrichment of survivin in exosomes from breast cancer cells treated with paclitaxel promotes cell survival and chemoresistance. Cancers (Basel) (2016) 8(12):E111. doi:10.3390/ cancers8120111

44. Yang SJ, Wang DD, Li J, Xu HZ, Shen HY, Chen X, et al. Predictive role of GSTP1-containing exosomes in chemotherapy-resistant breast cancer. Gene (2017) 623:5-14. doi:10.1016/j.gene.2017.04.031

45. Kavanagh EL, Lindsay S, Halasz M, Gubbins LC, Weiner-Gorzel K, Guang MHZ, et al. Protein and chemotherapy profiling of extracellular vesicles harvested from therapeutic induced senescent triple negative breast cancer cells. Oncogenesis (2017) 6(10):e388. doi:10.1038/oncsis.2017.82

46. Yang M, Chen J, Su F, Yu B, Su F, Lin L, et al. Microvesicles secreted by macrophages shuttle invasion-potentiating microRNAs into breast cancer cells. Mol Cancer (2011) 10:117. doi:10.1186/1476-4598-10-117

47. Jang JY, Lee JK, Jeon YK, Kim CW. Exosome derived from epigallocatechin gallate treated breast cancer cells suppresses tumor growth by inhibiting tumor-associated macrophage infiltration and M2 polarization. BMC Cancer (2013) 13:421. doi:10.1186/1471-2407-13-421

48. Melo SA, Sugimoto H, O'Connell JT, Kato N, Villanueva A, Vidal A, et al. Cancer exosomes perform cell-independent microRNA biogenesis and promote tumorigenesis. Cancer Cell (2014) 26(5):707-21. doi:10.1016/j.ccell.2014.09.005

49. Thakur BK, Zhang H, Becker A, Matei I, Huang Y, Costa-Silva B, et al. Doublestranded DNA in exosomes: a novel biomarker in cancer detection. Cell Res (2014) 24(6):766-9. doi:10.1038/cr.2014.44

50. Sansone P, Savini C, Kurelac I, Chang Q, Amato LB, Strillacci A, et al. Packaging and transfer of mitochondrial DNA via exosomes regulate escape from dormancy in hormonal therapy-resistant breast cancer. Proc Natl Acad Sci U S A (2017) 114(43):E9066-75. doi:10.1073/pnas.1704862114

51. O'Brien K, Rani S, Corcoran C, Wallace R, Hughes L, Friel AM, et al. Exosomes from triple-negative breast cancer cells can transfer phenotypic traits representing their cells of origin to secondary cells. Eur J Cancer (2013) 49(8):1845-59. doi:10.1016/j.ejca.2013.01.017

52. Palazzolo G, Albanese NN, DI Cara G, Gygax D, Vittorelli ML, Pucci-Minafra I. Proteomic analysis of exosome-like vesicles derived from breast cancer cells. Anticancer Res (2012) 32(3):847-60.

53. Harris DA, Patel SH, Gucek M, Hendrix A, Westbroek W, Taraska JW. Exosomes released from breast cancer carcinomas stimulate cell movement. PLoS One (2015) 10(3):e0117495. doi:10.1371/journal.pone.0117495

54. König L, Kasimir-Bauer S, Bittner AK, Hoffmann O, Wagner B, Santos Manvailer LF, et al. Elevated levels of extracellular vesicles are associated with therapy failure and disease progression in breast cancer patients undergoing neoadjuvant chemotherapy. Oncoimmunology (2017) 7(1):e1376153. doi:10.1080/2162402X.2017.1376153

55. Cappello F, Logozzi M, Campanella C, Bavisotto CC, Marcilla A, Properzi F, et al. Exosome levels in human body fluids: a tumor marker by themselves? Eur J Pharm Sci (2017) 96:93-8. doi:10.1016/j.ejps.2016.09.010
56. Logozzi M, Angelini DF, Iessi E, Mizzoni D, Di Raimo R, Federici C, et al. Increased PSA expression on prostate cancer exosomes in in vitro condition and in cancer patients. Cancer Lett (2017) 403:318-29. doi:10.1016/j. canlet.2017.06.036

57. Logozzi M, De Milito A, Lugini L, Borghi M, Calabrò L, Spada M, et al. High levels of exosomes expressing CD63 and caveolin-1 in plasma of melanoma patients. PLoS One (2009) 4(4):e5219. doi:10.1371/journal.pone.0005219

58. Gold B, Cankovic M, Furtado LV, Meier F, Gocke CD. Do circulating tumor cells, exosomes, and circulating tumor nucleic acids have clinical utility? A report of the association for molecular pathology. J Mol Diagn (2015) 17(3):209-24. doi:10.1016/j.jmoldx.2015.02.001

59. Szatanek R, Baj-Krzyworzeka M, Zimoch J, Lekka M, Siedlar M, Baran J. The methods of choice for extracellular vesicles (EVs) characterization. Int J Mol Sci (2017) 18(6):E1153. doi:10.3390/ijms18061153

60. Kasimir-Bauer S, Bittner AK, König L, Reiter K, Keller T, Kimmig R, et al. Does primary neoadjuvant systemic therapy eradicate minimal residual disease? Analysis of disseminated and circulating tumor cells before and after therapy. Breast Cancer Res (2016) 18(1):20. doi:10.1186/ s13058-016-0679-3

61. Galindo-Hernandez O, Villegas-Comonfort S, Candanedo F, GonzálezVázquez MC, Chavez-Ocaña S, Jimenez-Villanueva X, et al. Elevated concentration of microvesicles isolated from peripheral blood in breast cancer patients. Arch Med Res (2013) 44(3):208-14. doi:10.1016/j.arcmed.2013.03.002

62. Jia $\mathrm{Y}$, Chen $\mathrm{Y}$, Wang $\mathrm{Q}$, Jayasinghe U, Luo X, Wei Q, et al. Exosome: emerging biomarker in breast cancer. Oncotarget (2017) 8(25):41717-33. doi:10.18632/ oncotarget.16684

63. Yu DD, Wu Y, Shen HY, Lv MM, Chen WX, Zhang XH, et al. Exosomes in development, metastasis and drug resistance of breast cancer. Cancer Sci (2015) 106(8):959-64. doi:10.1111/cas.12715

64. Khan S, Bennit HF, Turay D, Perez M, Mirshahidi S, Yuan Y, et al. Early diagnostic value of survivin and its alternative splice variants in breast cancer. BMC Cancer (2014) 14:176. doi:10.1186/1471-2407-14-176

65. Chalmin F, Ladoire S, Mignot G, Vincent J, Bruchard M, Remy-Martin JP, et al. Membrane-associated Hsp72 from tumor-derived exosomes mediates STAT3dependent immunosuppressive function of mouse and human myeloidderived suppressor cells. J Clin Invest (2010) 120(2):457-71. doi:10.1172/ JCI40483

66. Sempere LF, Keto J, Fabbri M. Exosomal microRNAs in breast cancer towards diagnostic and therapeutic applications. Cancers (Basel) (2017) 9(7):E71. doi:10.3390/cancers9070071

67. Hannafon BN, Trigoso YD, Calloway CL, Zhao YD, Lum DH, Welm AL, et al. Plasma exosome microRNAs are indicative of breast cancer. Breast Cancer Res (2016) 18(1):90. doi:10.1186/s13058-016-0753-x

68. Zhou W, Fong MY, Min Y, Somlo G, Liu L, Palomares MR, et al. Cancersecreted miR-105 destroys vascular endothelial barriers to promote metastasis. Cancer Cell (2014) 25(4):501-15. doi:10.1016/j.ccr.2014.03.007

69. Eichelser C, Stückrath I, Müller V, Milde-Langosch K, Wikman H, Pantel K, et al. Increased serum levels of circulating exosomal microRNA-373 in receptor-negative breast cancer patients. Oncotarget (2014) 5(20):9650-63. doi:10.18632/oncotarget.2520

70. Rupp AK, Rupp C, Keller S, Brase JC, Ehehalt R, Fogel M, et al. Loss of EpCAM expression in breast cancer derived serum exosomes: role of proteolytic cleavage. Gynecol Oncol (2011) 122(2):437-46. doi:10.1016/j.ygyno.2011.04.035

71. Wang T, Ning K, Lu TX, Sun X, Jin L, Qi X, et al. Increasing circulating exosomes-carrying TRPC5 predicts chemoresistance in metastatic breast cancer patients. Cancer Sci (2017) 108(3):448-54. doi:10.1111/cas.13150

72. Aharon A, Sabbah A, Ben-Shaul S, Berkovich H, Loven D, Brenner B, et al. Chemotherapy administration to breast cancer patients affects extracellular vesicles thrombogenicity and function. Oncotarget (2017) 8(38):63265-80. doi:10.18632/oncotarget.18792

73. Melo SA, Luecke LB, Kahlert C, Fernandez AF, Gammon ST, Kaye J, et al. Glypican-1 identifies cancer exosomes and detects early pancreatic cancer. Nature (2015) 523(7559):177-82. doi:10.1038/nature14581

74. Matsuda K, Maruyama H, Guo F, Kleeff J, Itakura J, Matsumoto Y, et al. Glypican-1 is overexpressed in human breast cancer and modulates the mitogenic effects of multiple heparin-binding growth factors in breast cancer cells. Cancer Res (2001) 61(14):5562-9.

75. Kleeff J, Ishiwata T, Kumbasar A, Friess H, Büchler MW, Lander AD, et al. The cell-surface heparan sulfate proteoglycan glypican-1 regulates growth factor 
action in pancreatic carcinoma cells and is overexpressed in human pancreatic cancer. J Clin Invest (1998) 102(9):1662-73. doi:10.1172/JCI4105

76. Ciravolo V, Huber V, Ghedini GC, Venturelli E, Bianchi F, Campiglio M, et al. Potential role of HER2-overexpressing exosomes in countering trastuzumabbased therapy. J Cell Physiol (2012) 227(2):658-67. doi:10.1002/jcp.22773

77. König L, Kasimir-Bauer S, Hoffmann O, Bittner AK, Wagner B, Manvailer LF, et al. The prognostic impact of soluble and vesicular HLA-G and its relationship to circulating tumor cells in neoadjuvant treated breast cancer patients. Hum Immunol (2016) 77(9):791-9. doi:10.1016/j.humimm.2016.01.002

78. Martinez VG, O’Neill S, Salimu J, Breslin S, Clayton A, Crown J, et al. Resistance to HER2-targeted anti-cancer drugs is associated with immune evasion in cancer cells and their derived extracellular vesicles. Oncoimmunology (2017) 6(12):e1362530. doi:10.1080/2162402X.2017.1362530

79. Carosella ED, Rouas-Freiss N, Tronik-Le Roux D, Moreau P, LeMaoult J. HLA-G: an immune checkpoint molecule. Adv Immunol (2015) 127:33-144. doi:10.1016/bs.ai.2015.04.001

80. Carosella ED, Favier B, Rouas-Freiss N, Moreau P, Lemaoult J. Beyond the increasing complexity of the immunomodulatory HLA-G molecule. Blood (2008) 111(10):4862-70. doi:10.1182/blood-2007-12-127662

81. Poras I, Yaghi L, Martelli-Palomino G, Mendes-Junior CT, Muniz YC, Cagnin NF, et al. Haplotypes of the HLA-G 3' untranslated region respond to endogenous factors of HLA-G+ and HLA-G- cell lines differentially. PLoS One (2017) 12(1):e0169032. doi:10.1371/journal.pone.0169032

82. Nolan JP, Duggan E. Analysis of individual extracellular vesicles by flow cytometry. Methods Mol Biol (2018) 1678:79-92. doi:10.1007/978-1-49397346-0_5

83. Nolan JP. Flow cytometry of extracellular vesicles: potential, pitfalls, and prospects. Curr Protoc Cytom (2015) 73:1-16. doi:10.1002/0471142956.cy1314s73

84. van der PolE, van Gemert MJ, Sturk A, Nieuwland R, van Leeuwen TG. Singlevs. swarm detection of microparticles and exosomes by flow cytometry. J Thromb Haemost (2012) 10(5):919-30. doi:10.1111/j.1538-7836.2012.04683.x
85. Varga Z, Yuana Y, Grootemaat AE, van der Pol E, Gollwitzer C, Krumrey M, et al. Towards traceable size determination of extracellular vesicles. J Extracell Vesicles (2014) 4:3. doi:10.3402/jev.v3.23298

86. van der Pol E, de Rond L, Coumans FAW, Gool EL, Böing AN, Sturk A, et al. Absolute sizing and label-free identification of extracellular vesicles by flow cytometry. Nanomedicine (2018) 14(3):801-10. doi:10.1016/j.nano. 2017.12.012

87. Fais S, O’Driscoll L, Borras FE, Buzas E, Camussi G, Cappello F, et al. Evidencebased clinical use of nanoscale extracellular vesicles in nanomedicine. ACS Nano (2016) 10(4):3886-99. doi:10.1021/acsnano.5b08015

88. Iessi E, Logozzi M, Lugini L, Azzarito T, Federici C, Spugnini EP, et al. Acridine Orange/exosomes increase the delivery and the effectiveness of Acridine Orange in human melanoma cells: a new prototype for theranostics of tumors. J Enzyme Inhib Med Chem (2017) 32(1):648-57. doi:10.1080/14756366.2017 .1292263

89. Kusuzaki K, Matsubara T, Murata H, Logozzi M, Iessi E, Di Raimo R, et al. Natural extracellular nanovesicles and photodynamic molecules: is there a future for drug delivery? J Enzyme Inhib Med Chem (2017) 32(1):908-16. doi:10.1080/14756366.2017.1335310

Conflict of Interest Statement: The authors declare that the research was conducted in the absence of any commercial or financial relationships that could be construed as a potential conflict of interest.

Copyright (c) 2018 Schwich and Rebmann. This is an open-access article distributed under the terms of the Creative Commons Attribution License (CC BY). The use, distribution or reproduction in other forums is permitted, provided the original author(s) and the copyright owner are credited and that the original publication in this journal is cited, in accordance with accepted academic practice. No use, distribution or reproduction is permitted which does not comply with these terms. 